\title{
Hemodialysis Patients' Satisfaction and Associated Factors in National Teaching Hospital Hemodialysis Center, Cotonou (Benin)
}

\author{
Séraphin Ahoui1 ${ }^{*}$, Jacques Vigan², Bruno Léopold Agboton ${ }^{2}$, Evariste Eteka1, \\ Francis Tchegnonsi Tognon ${ }^{3}$, A. Anselme Djidonou3 ${ }^{3}$, Prosper Gandaho ${ }^{3}$, Leonard Fourn 4 \\ ${ }^{1}$ Department of Nephrology, Borgou Regional Teaching Hospital, Parakou, Benin \\ ${ }^{2}$ Nephrology-Hemodialysis University Clinic (CUNH), Hubert Koutoukou Maga National Teaching Hospital, Cotonou \\ (CNHU-HKM), Benin \\ ${ }^{3}$ Department of Psychiatry, Borgou Regional Teaching Hospital, Parakou, Benin \\ ${ }^{4}$ Faculty of Health Sciences, University of Abomey-Calavi, Abomey-Calavi, Benin \\ Email: *serahoui@yahoo.fr, *drserahoui@gmail.com
}

How to cite this paper: Ahoui, S., Vigan, J., Agboton, B.L., Eteka, E., Tognon, F.T., Anselme Djidonou, A., Gandaho, P. and Fourn, L. (2019) Hemodialysis Patients' Satisfaction and Associated Factors in National Teaching Hospital Hemodialysis Center, Cotonou (Benin). Open Journal of Nephrology, 9, 127-138. https://doi.org/10.4236/oineph.2019.94013

Received: September 19, 2019

Accepted: December 1, 2019

Published: December 4, 2019

Copyright $\odot 2019$ by author(s) and Scientific Research Publishing Inc. This work is licensed under the Creative Commons Attribution International License (CC BY 4.0).

http://creativecommons.org/licenses/by/4.0/

\begin{abstract}
Background: Patients' satisfaction is a relevant component in assessing healthcare services. The objective of this study was to study the level of satisfaction of chronic hemodialysis patients and the associated factors in Cotonou CNHU-HKM dialysis center. Patients and Methods: It was a cross-sectional, descriptive and analytical study conducted by administering a questionnaire on days off dialysis. It was carried out from $1^{\text {st }}$ November 2015 to $1^{\text {st }}$ January 2016 in CNHU-HKM Nephrology University Clinic of Cotonou. Hemodialysis patients aged 18 years and above having given their informed consent were included in the study. Patients' recruitment was comprehensive. Likert scale was used in assessing the level of satisfaction with 4 as "very satisfied" and 1 for "very dissatisfied". Satisfaction was evaluated on the basis of Ware dimensions. The threshold for satisfaction was 50. Outcomes: Overall, 377 patients were included in the study. Respondents' mean age was $51.5 \pm 13.3$ years with 1.37 as sex ratio. Arteriovenous fistula was used for $80.1 \%$ of hemodialysis patients. $77.7 \%$ of the patients underwent dialysis twice a week while $45.9 \%$ were administered a four-hour dialysis. The overall average proportion of "satisfied" was $76.5 \%$. The level of satisfaction was $52 \%$ for healthcare environment, $61 \%$ for service delivery, $73.9 \%$ for healthcare accessibility, $76.1 \%$ for healthcare structure, $77.5 \%$ for healthcare management, $90.3 \%$ for quality of healthcare, $88.3 \%$ for interpersonal relationship and $93.2 \%$ for efficiency and continuum of healthcare. Factors associated with satisfaction included age $(p=0.02)$, vascular access $(p=0.04)$ and urea reduction ratio $(p=$ 0.01 ). In addition, the degree of satisfaction of hemodialysis patients was not
\end{abstract}


statistically associated with sex, marital status, educational level, history of the disease, age of dialysis, number of sessions per week, and duration per session. Conclusion: The overall level of hemodialysis patients' satisfaction is above average. There is a need to particularly focus on healthcare environment, so as to better improve the level of satisfaction.

\section{Keywords}

Satisfaction, Chronic Hemodialysis, Cotonou

\section{Introduction}

Chronic Kidney Disease (CKD) is a devastating disease. It is quite often asymptomatic at the start and only reveals itself at end stage, thereby requiring replacement therapy [1]. CKD is treated through hemodialysis or peritoneal dialysis to mitigate impaired renal function and relieve the patient, without pretending to cure patients [2]. Dialysis is more common on other continents than in Africa. In 2005 the frequency of dialysis in the United States was estimated at 311 per million individuals per annum [3]. According to the World Health Organization (WHO), eight million individuals will need dialysis by 2025 [4]. In most countries, patients are placed on dialysis without seeking neither their opinion nor their level of acceptance and satisfaction. However, patients' opinion helps provide data on the ability of health professionals to effectively address their values and expectations [5]. The literature focuses on the level of patients' satisfaction which is regarded as a performance indicator for hospitals and health care programs [6].

Patient associations are created and fight to ensure that services rendered to patients are of high quality and meet their expectations [7]. In most countries, hemodialysis is a treatment that the patient undergoes without asking about his opinion, his level of acceptance or satisfaction. However, the patient's participation through his point of view is a relevant indicator of the quality of care for hemodialysis patients. This quality of care could guarantee an acceptable quality of life. The intervention of the patient in the medical decisions concerning him is essential for some years as an evidence and even more in the patient in chronic renal insufficiency under hemodialysis. It provided data on the ability of health professionals to respond effectively to patient values and expectations [8]. Since 1997, several satisfaction studies have been carried out, particularly in the general population, among hospitalized patients or patients in specialized consultations. A survey conducted in 2004 in the 12 structures of Lorraine (France) estimated overall satisfaction at $73.3 \%$ in hemodialysis with variability from one medical team to another [6]. In Africa, the first data from the Moroccan national dialysis register "Magredial" estimated in 2004 the prevalence of chronic end stage renal failure (CRTI) treated by hemodialysis at 162 per million inhabitants [9]. The level of such indicator is useful in identifying shortcomings in health 
services and undertaking adequate steps for improved healthcare quality [10]. In Benin, no scientific study has ever been conducted on the satisfaction of dialysis patients, hence the need for this study to assess the level of patients' satisfaction in CNHU-HKM hemodialysis center.

\section{Framework and Methods}

It was a cross sectional, descriptive and analytical study conducted over three months, from $1^{\text {st }}$ November 2015 to $1^{\text {st }}$ January 2016. The study population comprised all patients undergoing hemodialysis during the study period in CNHU-HKM Cotonou public dialysis center.

Individuals included in the study were hemodialysis patients aged 18 years and above, undergoing at least a three-month hemodialysis, able to answer questionnaire, and having given their informed consent. Patients who have been undergoing hemodialysis for less than three months, individuals suffering from acute kidney injury or those unable to answer the questionnaire were all excluded.

It was a comprehensive sampling which integrated all patients meeting inclusion criteria.

Satisfaction stands out as the dependent variable. Likert scale was used for assessing the level of satisfaction with 4 as "very satisfied", 3- "quite satisfied"; 2-"somewhat dissatisfied" and 1-"very dissatisfied" [11]. Pooling was conducted and scores 3 and 4 were considered "satisfied" while 1 and 2 were "dissatisfied". Patients' satisfaction was assessed on the basis of Ware dimensions while integrating our cultural background [10]. The relevant dimensions were: interpersonal relationships, technical quality of healthcare, healthcare accessibility, physical environment of healthcare, efficiency and healthcare continuum, availability and delivery of service. The threshold of satisfaction was 50. Independent variables included socio-demographic (age, sex and level of education), clinical (personal history and current health status) and hemodialysis related data (vascular access, seniority in dialysis, number of weekly session, duration of each session and urea reduction ratio). These data were collected during one-on-one interview on days off dialysis. Regarding unschooled patients, an iconography was used to gather their opinion based on various scores. Data entry and analysis was carried out with Epi Info version 7. Likert scale scores were analyzed by computing the ratio of each satisfaction dimension. Distribution tables were then developed through computing. Next, we clustered in two categories "dissatisfied" (somewhat dissatisfied and very dissatisfied) and "satisfied" (quite satisfied and very satisfied) the four initial categories of satisfaction. We computed the proportion of satisfied patients in each sub item. Thereafter, we calculated the average proportions of satisfied patients per each category, then we figured the average patients' averages to obtain the overall satisfaction. Chi squared test was used to compare "satisfied" and "dissatisfied" patients. The study was approved by the Technical Medical Board of selected hemodialysis units. Anonymity and confidentiality of data were maintained in line with ethi- 
cal principles for medical research involving human subjects as outlined in the World Medical Association Declaration of Helsinki [12].

\section{Outcomes}

During the study period, 392 hemodialysis patients met our criteria, however, 15 were excluded among which nine men. Overall, 377 patients were included in the study, representing $96.2 \%$.

\subsection{Socio-Demographic Features}

Respondents' mean age was $51.5 \pm 13.3$ years (extreme values estimated at 19 and 79 years). Most respondents were between 55 and 64 years (28.6\%). Men outnumber women in a proportion of $57.8 \%$ with 1.37 as sex ratio. In our study, $166(44.0 \%)$ hemodialysis patients had high school education.

\subsection{Clinical Features}

HBP history was prevalent, with $81.2 \%$ frequency against $22.5 \%$ for diabetes. $80.1 \%$ of respondents had their arteriovenous fistula functioning properly. 293 (77.7\%) had two dialysis sessions on weekly basis. Regarding duration, 173 (45.9\%) patients underwent a four-hour dialysis. Seniority in dialysis ranged from 5 to 10 years in 138 (36.6\%) respondents. Urea reduction ratio is greater than $60 \%$ for $313(83 \%)$ patients (Table 1$)$.

\subsection{Hemodialysis Patients' Satisfaction}

The overall average proportion of satisfied patients was $76.5 \%$. Figure 1 highlights the distribution of the average proportion of satisfied patients per each dimension.

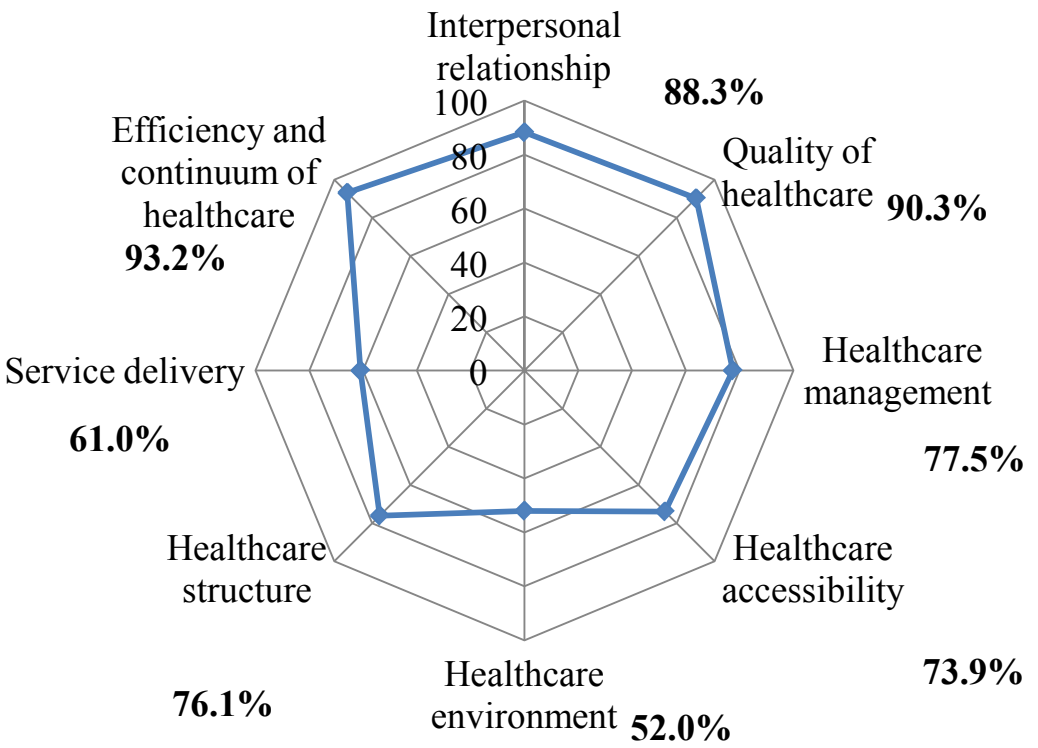

Figure 1. Distribution of satisfied patients' average proportion per each dimension, CNHU-HKM Cotonou dialysis center, 2016. 
Table 1. Patients' distribution per socio-demographic, clinical and dialysis features in CNHU-HKM Cotonou dialysis center, 2016.

\begin{tabular}{|c|c|c|}
\hline & Size $(\mathrm{n}=377)$ & $(\%)$ \\
\hline \multicolumn{3}{|l|}{ History } \\
\hline Diabetes & 85 & 22.5 \\
\hline High Blood Pressure & 306 & 81.2 \\
\hline Other & 12 & 3.18 \\
\hline No & 08 & 2.12 \\
\hline \multicolumn{3}{|c|}{ Seniority in dialysis (years) } \\
\hline$<2$ & 35 & 9.3 \\
\hline $2-5$ & 96 & 25.5 \\
\hline $5-10$ & 138 & 36.6 \\
\hline$>10$ & 108 & 28.6 \\
\hline \multicolumn{3}{|c|}{ Number of weekly dialysis session } \\
\hline 2 & 293 & 77.7 \\
\hline 3 & 84 & 22.3 \\
\hline \multicolumn{3}{|c|}{ Duration per dialysis session } \\
\hline $4 \mathrm{~h}$ & 173 & 45.9 \\
\hline $4 \mathrm{~h} 30$ & 72 & 19.1 \\
\hline $5 \mathrm{~h}$ & 132 & 35.0 \\
\hline \multicolumn{3}{|l|}{ Vascular access } \\
\hline Arteriovenous fistula & 302 & 80.1 \\
\hline \multicolumn{3}{|l|}{ Urea reduction ratio } \\
\hline$\geq 60$ & 283 & 75.1 \\
\hline
\end{tabular}

\subsection{Hemodialysis Patients' Opinions on Interpersonal Relations in Healthcare, Quality of Service and Healthcare Management, Efficiency and Continuum of Healthcare}

The majority of hemodialysis patients (89.4\%) were quite satisfied with the nephrologist interaction with them. With regard to accuracy of the information provided by the nephrologist and confidentiality during the clinical examination, hemodialysis patients were very satisfied in a proportion of $94.2 \%$ and $92 \%$ respectively. Concerning the nephrologist's care and attention, the way he ensures the accuracy of the quantity of dialysis received, the quality management of new medical issued by the dialysis center and the quantity of fluid extracted during a dialysis session, hemodialysis patients were very satisfied in a proportion of $87.8 \%, 87 \%, 85.9 \%$ and $80.9 \%$ respectively. Regarding coordination of care between the nephrologist and other doctors, the response from the dialysis center in cases of distress or worries, and information provided about the required quantity of fluid intake within dialysis sessions, hemodialysis patients were very satisfied in a proportion of $66.8 \%, 84.4 \%$ and $88.6 \%$ respectively. As 
for information provided on dialysis $44.6 \%$ of hemodialysis patients were rather satisfied. Information provided by the nephrologist to hemodialysis patients were considered satisfactory (85.1\%). The majority of hemodialysis patients $(98 \%)$ recommended the dialysis center to their acquaintances or relatives suffering from the same disease. Table 2 highlights hemodialysis patients' classification according to their opinions about interpersonal relationship in healthcare, quality of service and healthcare management, efficiency and continuum of healthcare.

\subsection{Opinions of Hemodialysis Patients on Access to Healthcare, Care Environment, Healthcare Structure and Service Delivery}

In our study, $77 \%$ of hemodialysis patients were satisfied with the easy access in contacting the nephrologist. Hemodialysis patients were very satisfied with the availability and accessibility to the hemodialysis center in a proportion of $72.42 \%$ and $83.6 \%$ respectively. Moreover, $87.8 \%$ of them were pleased with having

Table 2. Hemodialysis patients' distribution per their opinion on interpersonal relationships in healthcare, quality of service and healthcare management, effectiveness and continuum of healthcare in CNHU-HKM Cotonou dialysis center, 2016.

\begin{tabular}{|c|c|c|c|c|c|c|c|c|}
\hline & \multicolumn{2}{|c|}{$\begin{array}{c}\text { Very } \\
\text { dissatisfied }\end{array}$} & \multicolumn{2}{|c|}{$\begin{array}{l}\text { Somewhat } \\
\text { dissatisfied }\end{array}$} & \multicolumn{2}{|c|}{$\begin{array}{l}\text { Quite } \\
\text { satisfied }\end{array}$} & \multicolumn{2}{|c|}{$\begin{array}{c}\text { Very } \\
\text { satisfied }\end{array}$} \\
\hline & $\mathbf{N}$ & $\%$ & $\mathbf{N}$ & $\%$ & $\mathbf{N}$ & $\%$ & $\mathbf{N}$ & $\%$ \\
\hline \multicolumn{9}{|l|}{ Interpersonal relationship in healthcare } \\
\hline Nephrologist mood & 0 & 0.0 & 25 & 6.6 & 337 & 89.4 & 15 & 3.9 \\
\hline Hygiene measures & 1 & 0.3 & 48 & 12.7 & 303 & 80.4 & 25 & 6.6 \\
\hline Support and care & 1 & 0.3 & 48 & 12.7 & 303 & 80.4 & 25 & 6.6 \\
\hline Staff friendliness & 1 & 0.3 & 52 & 13.8 & 299 & 79.3 & 25 & 6.6 \\
\hline \multicolumn{9}{|l|}{ Quality of healthcare } \\
\hline Care provided by the nephrologist & 4 & 1.1 & 22 & 5.8 & 331 & 87.8 & 20 & 5.3 \\
\hline Nephrologist information & 0 & 0 & 14 & 3.7 & 355 & 94.2 & 8 & 2.1 \\
\hline Dialysis technique & 0 & 0 & 44 & 11.7 & 328 & 87.0 & 5 & 1.3 \\
\hline removing excess water & 3 & 0.8 & 64 & 17.0 & 305 & 80.9 & 5 & 1.3 \\
\hline Other health issues & 4 & 1.1 & 42 & 11.1 & 324 & 85.9 & 7 & 1.9 \\
\hline Privacy & 0 & 0.0 & 23 & 6.1 & 347 & 92.0 & 7 & 1.9 \\
\hline \multicolumn{9}{|l|}{ Healthcare management } \\
\hline Healthcare coordination & 9 & 2.4 & 61 & 16.2 & 252 & 66.8 & 55 & 14.6 \\
\hline Dialysis center responsiveness & 0 & 0 & 48 & 12.7 & 318 & 84.4 & 11 & 2.9 \\
\hline Information on dialysis & 22 & 5.8 & 168 & 44.6 & 158 & 41.9 & 29 & 7.7 \\
\hline $\begin{array}{l}\text { Quantity of fluid intake } \\
\text { in-between dialysis sessions }\end{array}$ & 3 & 0.8 & 29 & 7.7 & 334 & 88.6 & 11 & 2.9 \\
\hline \multicolumn{9}{|c|}{ Effectiveness and continuum of healthcare } \\
\hline Accuracy of nephrologist information & 1 & 0.3 & 55 & 14.6 & 312 & 82.7 & 9 & 2.4 \\
\hline Better healthcare measures & 0 & 0.0 & 1 & 0.3 & 170 & 45.1 & 206 & 54.6 \\
\hline Dialysis center recommendation & 0 & 0.0 & 8 & 2.1 & 354 & 93.9 & 15 & 4.0 \\
\hline
\end{tabular}


access to the patient's file. However, $48.3 \%$ of patients were dissatisfied with the frequency of the nephrologist visit. As for the physical environment of healthcare, only $18.5 \%$ expressed satisfaction with safe handling and movement equipment, $43 \%$ with dialysis bed or chair; but over half of them were satisfied with the provisions of transport and furniture in the waiting-room. Respondents were satisfied with dialysis room lighting and space in a proportion of $91.5 \%$ and $88.6 \%$ respectively. Concerning cleanliness of the premises, $50.6 \%$ of patients were satisfied. With respect to the dialysis center opening hours and noise, they were satisfied in a proportion of $77.5 \%$ and $82.8 \%$ respectively. For snack, $76.2 \%$ of patients expressed dissatisfaction. Table 2 and Table 3 highlight hemodialysis

Table 3. Hemodialysis patients' distribution per their opinion on healthcare accessibility, physical environment of healthcare, service delivery, and healthcare structure in CNHU-HKM Cotonou dialysis center, 2016.

\begin{tabular}{|c|c|c|c|c|c|c|c|c|}
\hline & \multicolumn{2}{|c|}{$\begin{array}{c}\text { Very } \\
\text { dissatisfied }\end{array}$} & \multicolumn{2}{|c|}{$\begin{array}{l}\text { Somewhat } \\
\text { dissatisfied }\end{array}$} & \multicolumn{2}{|c|}{$\begin{array}{l}\text { Quite } \\
\text { satisfied }\end{array}$} & \multicolumn{2}{|c|}{$\begin{array}{c}\text { Very } \\
\text { satisfied }\end{array}$} \\
\hline & $\mathbf{N}$ & $\%$ & $\mathbf{N}$ & $\%$ & $\mathbf{N}$ & $\%$ & $\mathbf{N}$ & $\%$ \\
\hline \multicolumn{9}{|l|}{ Access to healthcare } \\
\hline Nephrologist accessibility & 13 & 3.5 & 71 & 18.8 & 267 & 70.8 & 26 & 6.9 \\
\hline Frequency nephrologist visit & 14 & 3.7 & 182 & 48.3 & 160 & 42.4 & 21 & 5.6 \\
\hline $\begin{array}{l}\text { Dialysis center } \\
\text { accessibility through phone call }\end{array}$ & 13 & 3.5 & 71 & 18.8 & 267 & 70.8 & 26 & 6.9 \\
\hline $\begin{array}{l}\text { Dialysis center responsiveness } \\
\text { in the event of emergency }\end{array}$ & 1 & 0.3 & 61 & 16.2 & 312 & 82.8 & 3 & 0.8 \\
\hline Dialysis center accessibility & 1 & 0.3 & 103 & 27.3 & 264 & 70.0 & 9 & 2.4 \\
\hline Access to patient's file & 2 & 0.5 & 34 & 9.0 & 312 & 82.8 & 19 & 5.0 \\
\hline Overall quality of healthcare & 0 & 0.0 & 113 & 30.0 & 241 & 63.9 & 23 & 6.1 \\
\hline \multicolumn{9}{|l|}{ Healthcare environment } \\
\hline $\begin{array}{l}\text { Equipment facilitating } \\
\text { movement and handling }\end{array}$ & 64 & 17 & 243 & 64.5 & 70 & 18.5 & 0 & 0.0 \\
\hline Transport & 1 & 0.3 & 111 & 29.4 & 264 & 70.0 & 1 & 0.3 \\
\hline Dialysis bed or chair & 18 & 4.8 & 207 & 54.9 & 148 & 39.3 & 4 & 1.0 \\
\hline Access and quality of dressing room & 13 & 3.4 & 129 & 34.2 & 234 & 62.1 & 1 & 0.3 \\
\hline Comfort waiting room furniture & 1 & 0.3 & 117 & 31.0 & 255 & 67.6 & 4 & 1.1 \\
\hline \multicolumn{9}{|l|}{ Healthcare structure } \\
\hline Dialysis room space & 0 & 0.0 & 43 & 11.4 & 333 & 88.3 & 1 & 0.3 \\
\hline Lighting in patient rooms & 0 & 0.0 & 33 & 8.8 & 341 & 90.5 & 3 & 0.8 \\
\hline Rooms temperature & 0 & 0.0 & 98 & 26.0 & 256 & 67.9 & 23 & 6.1 \\
\hline Rooms cleanliness & 10 & 2.7 & 176 & 46.7 & 180 & 47.7 & 11 & 2.9 \\
\hline \multicolumn{9}{|l|}{ Service delivery } \\
\hline Dialysis center opening hours & 0 & 0.0 & 85 & 22.5 & 285 & 75.6 & 7 & 1.9 \\
\hline Noise dialysis room & 2 & 0.5 & 63 & 16.7 & 306 & 81.2 & 6 & 1.6 \\
\hline Snack & 61 & 16.2 & 230 & 61.0 & 85 & 22.5 & 1 & 0.3 \\
\hline
\end{tabular}


patients' classification according to their opinion on access to healthcare, the environment, service delivery, and healthcare structure in CNHU-HKM Cotonou dialysis center, 2016.

\subsection{Identification of Factors Associated with Hemodialysis Patients' Satisfaction}

Patients' satisfaction was statistically associated with age $(\mathrm{p}=0.02)$, vascular access $(p=0.04)$ and urea reduction ratio $(p=0.01)$. However, sex $(p=0.59)$, marital status $(\mathrm{p}=0.86)$ educational level $(\mathrm{p}=0.79)$, history of the disease $(\mathrm{p}=$ $0.44)$, seniority in dialysis $(\mathrm{p}=033)$, number of weekly session $(\mathrm{p}=0.55)$ and the duration per each session $(\mathrm{p}=0.74)$ were not statistically associated with hemodialysis patients' satisfaction. Table 4 and Table 5 outline the relationship between socio-demography, clinical, dialysis features and the level of patients' satisfaction in CNHU-HKM Cotonou dialysis center, 2016.

Table 4. Factors associated with the level of patients' satisfaction in CNHU-HKM Cotonou dialysis center, 2016.

\begin{tabular}{|c|c|c|c|c|c|}
\hline & \multicolumn{2}{|c|}{ Dissatisfied } & \multicolumn{2}{|c|}{ Satisfied } & \multirow{2}{*}{$\mathbf{P}$} \\
\hline & $\mathrm{n}$ & $\%$ & $\mathrm{n}$ & $\%$ & \\
\hline Age & & & & & 0.02 \\
\hline$<45$ & 69 & 60.5 & 45 & 39.5 & \\
\hline $45-65$ & 88 & 44.0 & 112 & 56.0 & \\
\hline$>65$ & 30 & 47.6 & 33 & 52.4 & \\
\hline Vascular access & & & & & 0.04 \\
\hline central venous catheter & 39 & 52.0 & 36 & 48.0 & \\
\hline Arteriovenous fistula & 121 & 40.1 & 181 & 59.9 & \\
\hline Urea reduction ratio & & & & & 0.01 \\
\hline$<60$ & 29 & 30.9 & 65 & 69.1 & \\
\hline$\geq 60$ & 131 & 46.3 & 152 & 53.7 & \\
\hline
\end{tabular}

Table 5. Factors not associated with the level of patients' satisfaction in CNHU-HKM Cotonou dialysis center, 2016.

\begin{tabular}{|c|c|c|c|c|c|}
\hline & \multicolumn{2}{|c|}{ Dissatisfied } & \multicolumn{2}{|c|}{ Satisfied } & \multirow{2}{*}{$\mathbf{P}$} \\
\hline & $\mathbf{n}$ & $\%$ & $\mathbf{n}$ & $\%$ & \\
\hline Marital status & & & & & 0.86 \\
\hline Married & 120 & 42.7 & 161 & 57.3 & \\
\hline Unmarried & 40 & 41.7 & 56 & 58.3 & \\
\hline Educational level & & & & & 0.79 \\
\hline Unschooled & 16 & 44.4 & 20 & 55.6 & \\
\hline Schooled & 144 & 42.2 & 197 & 57.8 & \\
\hline History & & & & & 0.44 \\
\hline
\end{tabular}




\begin{tabular}{|c|c|c|c|c|c|}
\hline Continued & & & & & \\
\hline Diabetes & 40 & 47.1 & 45 & 52.9 & \\
\hline HBP & 127 & 41.5 & 179 & 58.5 & \\
\hline Age (years) & & & & & 0.33 \\
\hline$<5$ & 60 & 45.8 & 71 & 54.2 & \\
\hline$\geq 5$ & 100 & 40.7 & 146 & 59.3 & \\
\hline Number of dialysis session & & & & & 0.55 \\
\hline 2 & 122 & 41.6 & 171 & 58.4 & \\
\hline 3 & 38 & 45.2 & 46 & 54.8 & \\
\hline Duration of dialysis session & & & & & 0.74 \\
\hline$<4 \mathrm{~h}$ & 75 & 43.4 & 98 & 56.6 & \\
\hline$\geq 4 \mathrm{~h}$ & 85 & 41.7 & 119 & 58.3 & \\
\hline
\end{tabular}

\section{Discussion}

Our study was the first ever conducted on patients' satisfaction in CNHU HKM hemodialysis center.

The study was conducted in a single dialysis service limiting the lack of homogeneity of practices responsible for bias indication and difference of practices. Certainly, the complexity of the measurement of satisfaction has led to the existence of several dimensions and measurement tools. We chose the Ware model validated and used in several other works to limit information bias [10]. The questionnaires were written in French while some people in the study population were out of school leading to the use of information images. Translating questions and images into local languages could possibly lead to information bias. It could have been translated into language and then translated back into French to check the tool's accuracy.

The overall average score of satisfied hemodialysis patients was $76.5 \%$. This score is higher than $63.3 \%$ reported by Nguyen Thi [13]. This could be explained by sampling size and the monocentric nature of our study.

\subsection{Patients' Opinion on the Various Dimensions}

In our study, satisfaction with interpersonal relationship in healthcare services is much better with the doctor than with allied health professionals. A survey conducted in Brazzaville [14] reported good hemodialysis patients' relationship with doctors, which is consistent with that of our study. Some other patients are satisfied with neither doctors nor allied health professionals, which suggests an inferiority complex due to their disease influencing their judgment towards caregivers as shown in several literatures [15] [16] [17].

The proportion of patients satisfied with respect for their privacy by health workers in our study is lower than that of the study conducted in Lyon, France in 2010 [18]. This variance may be due to the strict compliance with privacy in France unlike African countries such as Benin. In addition, results reported in 
France revealed quicker reactiveness in hemodialysis patients management than in our study [18]. This is probably related to the highly developed technical facilities and the conscientiousness in the provision of healthcare in developed countries.

Over four out of six hemodialysis patients expressed positive opinion on the coordination of healthcare activities in the dialysis unit. According to them, the dialysis unit met their care needs. This result is consistent with the records contained in a study conducted in France in 2012 [19].

In our study, the level of satisfaction in terms of the dialysis center's readiness to assist you in case of emergency is higher than the one reported in Dakar in 2015 [20]. The frequency of the nephrologist visit to the center is globally low [13], and even lower in our study. This is explained by the fact that the dialysis center is open 24 hours weekly for dialysis sessions yet, patients want the nephrologist to often pay then a visit. The point is that, apart from attending to the dialysis center, the nephrologist carries out training and researches which require to spend time away from his patients. According to respondents, access to dialysis patient's file was satisfactory. These observations are similar to the results recorded in the Dakar study [20]. The comfort of the dialysis bed or chair disappointed patients who expressed dissatisfaction. This dissatisfaction is also expressed for equipment used for moving and handling dialysis patients. Their opinion improved a bit on dressing rooms and furniture provided in the waiting room. Moreover, they expressed satisfaction on the dialysis room lighting and space. This finding is consistent with the study conducted in Dakar; the setting is approved by the vast majority of patients certainly because it meets the minimum standard of comfort [20]. On the other hand, the level of satisfaction for cleanliness of the premises is much lower than data reported in a study carried out in France in 2012 [19]. This reflects poor departmental head supervision of the caregivers responsible for cleaning rooms after each dialysis sessions. In fact, the supervisor should instill discipline.

Over three quarters of the patients said they were satisfied with the dialysis center's opening hours and the sound and peaceful atmosphere in the room. Less than quarter of them were satisfied with the snack. These results are similar to the observation in many studies in Africa [16] [17] where food plays an important role culturally.

\subsection{Factors Associated with Hemodialysis Patients' Satisfaction}

There was a statistically significant relation between the age of dialysis patients and the level of satisfaction $(\mathrm{p}=0.02)$. Older respondents express a higher level of satisfaction. This finding is similar in many studies [21] including that of Nguyen Thi et al. [13]. This could be explained by the fact that the levels of care expected are different according to age [22], and also due to the fact that in the African culture we show a lot of respect and care towards elderly people.

Satisfaction is also associated with vascular access $(\mathrm{p}=0.04)$; patients with ar- 
teriovenous fistula are more satisfied. The use of arteriovenous fistula has been a common practice in several studies [10] [20] as is convenient for many patients, certainly because it reduces the risk of infection unless patients with central venous catheters much more exposed [22].

Urea reduction ratio (URR) is statistically related to satisfaction ( $p=0.01$ ). The better the URR, the more satisfied patients are. In other studies, including that of Kane et al. [23], the current health status is also associated with satisfaction. Patients would be more easily focused on their current health status in relation to the care they have been provided [10].

\section{Conclusion}

The overall level of satisfaction expressed by hemodialysis patients exceeds the average. There is a need to particularly focus on the quality of healthcare for better management of hemodialysis patients. Patients' satisfaction should be assessed more often as it is the true indicator of hospital performance.

\section{Conflicts of Interest}

The authors declare no conflicts of interest regarding the publication of this paper.

\section{References}

[1] Bouhabel, A., Laib, Z., Hannache, K. and Aberkane, A. (2014) Renal Replacement Therapy by Hemodialysis in Constantine (Algeria): Overview. Nephrology \& Therapeutics, 10, 39-43. https://doi.org/10.1016/j.nephro.2013.07.371

[2] Cupa, D. (2002) Psychology Nephrology. EDK, Paris, 10-21. https://doi.org/10.3917/edk.cupa.2002.01

[3] Benghanem Gharbi, M., Dkhissi, H., Fassi Fehri, S. and Lemseffer, Y. (2005) Recommendations of the Moroccan Society of Nephrology for a Comprehensive Strategy for the Management of Chronic Renal Failure. ALD 17, Morocco.

[4] Berney, C., Fessler, C., Abu Khalil, S., Molliqaj Villard, N. and Arlettaz, Y. (2010) What Does the Diagnosis of Chronic Renal Failure in Geneva? Report Immersion Unit in Medicine. Community Switzerland, 6-7.

[5] Donabedian, A. (1988) The Quality of Care. How Can It Be Assessed? The Journal of the American Medical Association, 260, 1743-1748. https://doi.org/10.1001/jama.1988.03410120089033

[6] Rodenberg, S.N. (1990) Choosing the Assessment Method that Meets Your Needs. In: Graham, N.O., Ed., Quality Assurance in Hospitals, Aspen Publishers Inc., Rockville, MD.

[7] Lopez, A. and Remy, P.-L. (2007) Mesures de la satisfaction des usagers des établissements de santé. Rapport No. 2007-045P (MARS 2007). Inspection Générale des Affaires Sociales (IGAS), Paris. [en ligne] http://www.ladocumentationfrancaise.fr/var/storage/rapports-publics/074000592.pdf

[8] Haute autorité de la santé (2014) Évaluation médico-économique des stratégies de prise en charge de l'insuffisance rénale chronique terminale en France. [en ligne] http://www.has-sante.fr/jcms/c_1775180/fr/evaluation-medico-economique-des-str ategies-de-prise-en-charge-de-l-insuffisance-renale-chronique-terminale-en-france 
[9] Driss, Z., El Hocein, D., Loubna, B., et al. (2013) Recommandations de la société marocaine de néphrologie pour une stratégie globale de la prise en charge de l'insuffisance rénale chronique. ALD 17, Maroc.

[10] Pourin, C., Barberger-Gateau, P., Michel, P. and Solomon, R. (1999) The Satisfaction Measurement of Hospitalized Patients. Part 1: Conceptual Aspects and Review Work. Journal Clinical Oncology, 17, 101-115.

[11] Esqalli, I., Knidiri, H., Fadili, W., et al. (2013) Are Our Hemodialysis Satisfied with Respect to Care? Nephrology \& Therapeutics, 9, 299.

[12] WMA (2013) Declaration of Helsinki-Ethical Principles for Medical Research Involving Human Subjects. 64th General Assembly, Fortaleza, Brazil, October 2013.

[13] Nguyen Thi, P.L., Frimat, L., Loos-Ayav, C., Kessler, M. and Briançon, S. (2008) Questionnaire SDIALOR: Instrument to Measure the Satisfaction of Dialysis Patients. Néphrologie \& Thérapeutique, 4, 266-277. https://doi.org/10.1016/j.nephro.2008.02.006

[14] Itoua, C., Ambeto Obemda, F.S., Mbemda Moutounou, G.M., et al. (2014) Satisfaction Year Obstetrical Patients University Hospital in Brazzaville, Congo. Médecine d'Afrique Noire, 61, 418-423.

[15] Alloh, D., Aka, N., Manu, B., Bombo, J., Kouakou, J. and Pillah, L. (2011) Evaluation of Satisfaction Rehabilitation Day Hospital Patients in Abidjan. Black African Medicine, 58, 64-68.

[16] Ouedraogo, A., Zongo, J. and Zamane, H. (2013) Evaluation of Satisfaction of the Beneficiaries of the Offer of Care in Maternity Hospitals in the City of Ouagadougou. In: Book of Abstracts, Sixth Congress of the Society of Obstetricians and Gynecologists of Burkina, Ouagadougou, 33.

[17] Kafando, B., Drabo, M.K., Tarnagda, Z. and Konfe, S. (2010) User Satisfaction of Healthcare Provision Services of the Central Plateau Region of Burkina Faso. African black Medicine, 57, 593-600.

[18] Laure, B. (2010) Lyon Hospitals: Results of the Survey Saphora 2010-2011. http://www.chu-lyon.fr/web/3739

[19] Aural, F.E. (2012) Dialysis Patient Satisfaction Measurement Survey in 2012. https://www.aural.fr/public_files/fck/Rapport_Enquete_satisfaction_patients_dialys es_2014.pdf

[20] Ka, E.F., Keita, Y., Cisse, M.M., Saffraoui, O., Lemrabott, A.T., Faye, M., Abdoul Karim, D., et al. (2015) Study Satisfaction Hemodialysis Patients: About 211 Chronic Hemodialysis Patients in Dakar. Nephrology \& Therapeutics, 11, 302. https://doi.org/10.1016/j.nephro.2015.07.105

[21] Rubin, R.H. (1990) Can Patients Evaluate-The Quality of Care? Medical Care Research and Review, 47, 267-326. https://doi.org/10.1177/107755879004700302

[22] Schmalz-Ott, S., Monti, M. and Vollenweider, P. (2008) Establishment of a Central Venous Catheter in Adults. Revue Médicale Suisse, 4, 2343-2348.

[23] Kane, R.L., Finch, M. and Maciejewski, M. (1997) The Relationship of Patient Satisfaction with Care and Clinical Outcomes. Medical Care, 35, 714-730.

https://doi.org/10.1097/00005650-199707000-00005 